\title{
SubjeTIVIDAde E OBjeTIVAÇÃo os Dilemas da Modernidade Segundo Simmel E Weber
}

\section{Bruno Sciberras de Carvalho ${ }^{1}$}

A construção teórica de Max Weber e Georg Simmel referente aos problemas propostos pela modernidade demonstra a singularidade das sociedades modernas em manifestar uma relação entre indivíduo e estrutura social, na qual ocorre uma intensa objetivação que questiona os pressupostos de subjetividade da contemporaneidade. A fim de revelar a direção deste processo, ambos os autores recorrem a uma reconstituição histórica em que buscam identificar as características fundamentais da sociedade moderna em oposição às outras formações sociais. Nesse sentido, a conceituação de Simmel da sociedade monetariamente desenvolvida em contraste às economias não monetárias, e a diferenciação de Weber entre as sociedades tradicionais e aquelas baseadas na racionalidade ocidental, podem ser percebidas dentro de um contexto teórico em que se constroem pares dicotômicos que enfatizam, sobretudo, a particularidade da nova organização social em desenvolvimento. Outras análises manifestavam a mesma preocupação, como pode ser percebido nas oposições entre a comunidade e a sociedade de Tönnies, e os tipos de solidariedade orgânica e mecânica de Durkheim. Entretanto, as análises de Simmel e Weber possuem a particularidade de focalizar a força de uma realidade objetiva caracterizada por um tipo de racionalidade que contraria o otimismo iluminista na liberdade individual e na igualdade que influenciou parte da moderna teoria social e política.

Nesse sentido, pode-se detectar nos trabalhos de Simmel e Weber uma distinção entre manifestações de racionalidade objetiva e de subjetividade que condiz com a tese central da dialética da modernidade esboçada, posteriormente, por exemplo, pela Teoria Crítica. Enquanto Simmel indica uma separação cada vez maior, representada pela dimensão monetária, entre a subjetividade individual e os produtos objetivos das interações

1 Doutorando em Ciência Política no IUPERJ. 
sociais, o processo de racionalização exposto por Weber especifica que, ao mesmo tempo em que é dado a este indivíduo a oportunidade de esclarecimento quanto a seus valores, libertando-o das antigas magias e ilusões, tendências culturais coercitivas seriam criadas, representadas, principalmente, pelo Estado moderno burocratizado. Enfim, manifestase um processo paradoxal, em que as mesmas forças estruturais que libertam o homem, o dominam logo em seguida.

As singularidades de cada autor serão delineadas a seguir, de forma a procurar explicitar a consonância de suas teorias em relação a este dilema. Primeiramente, éindicada a composição teórica de Simmel sobre a tendência da modernidade em efetuar uma desconexão entre as dimensões objetiva e subjetiva. Posteriormente, são demarcadas as analogias que este entendimento possui em relação à concepção de dominação racional-legal presente na teoria de Weber, quesalienta, sobretudo, uma direção dasociedade modernaà objetivação. Afinalidade central é sublinhar a relevância de ambas as teorias na percepção de uma esfera objetiva que, justamenteem um contexto social que pressupõe o rompimento de fundamentos tradicionais, subverte o advento da subjetividade e da liberdade individual.

\section{Simmel e A Desconexão EnTre as Culturas Subjetiva e Objetiva}

Simmel expõe os dilemas da modernidade ao caracterizar as relações entre agência e sociedade a partir de uma objetivação da dimensão subjetiva. A análise do conceito de cultura que Simmel apresenta, estabelece, claramente, as relações desconexas da ação humana moderna com os objetos por ela elaborados. ${ }^{2}$ Segundo o autor, a cultura está relacionada com a idéia de cultivo, ou seja, com a ingerência exterior que possibilita o desenvolvimento de um objeto determinado de acordo com sua natureza e disposições específicas. Este desenvolvimento não poderia ser obtido por meio do progresso espontâneo que emerge das qualidades subjetivas do objeto em questão, mas através de uma intervenção que segue suas inclinações, sendo esta intervenção denominada cultura. Deve-se notar que Simmel indica o homem como a matéria mais inclinada ao cultivo, já que é o único ser em que a direção à perfeição é presumida desde 0 início. ${ }^{3}$ Somente a alma humana conteria as potencialidades de desenvolvimento cujas finalidades são, necessariamente, determinadas por uma intervenção externa e deliberada.

2 Cf. Simmel, Georg. "Subjective Culture" in On Individuality and Social Forms. Chicago: The University of Chicago Press, 1971.

3 Id. Ibid. pp. 229-30. 
As relações da cultura subjetiva com a objetiva tornam-se mais claras quando se nota que a cultura existe somente quando o homem atrai algo externo a ele. As formas de comportamento humano, por exemplo, se caracterizam como formação cultural na medida em que o desenvolvimento do indivíduo pressupõe uma direção para esferas objetivas, reais ou ideais, fora do self, constituindo uma combinação teleológica entre sujeito e objeto. Estar vivo seria ter uma pretensão quase natural em produzir e redefinir obras de cultura. Por outro lado, a cultura é criada quando esse desenvolvimento é ordenado em consonância com a estrutura total da alma subjetiva. Simmel lembra que os mais impressionantes trabalhos e pensamentos podem, quando não se transpõem ou cooperam com outros elementos da ordem objetiva, não possuir relevância cultural, permanecendo em uma restrita posição subjetiva. ${ }^{4}$

Oproblema caracterizado por Simmel apareceno momento em que há umaseparação do produto cultural em relação ao seu criador. É neste instante que a cultura pode ser dividida em duas esferas distintas: a cultura objetiva, que designa objetos em estado de evolução; e a cultura subjetiva, referente ao nível de desenvolvimento interior que as pessoas alcançam. Quanto maisseparado um produto estáem relação à espiritualidade subjetivade seuscriadores, mais ele passa a ser integrado dentro de uma ordem exclusivamente objetiva. Ocorre, então, uma inversão das relações entre sujeito e objeto. 0 cultivo dos conteúdos objetivos reverte a ordem do processo cultural real dos homens, já que a finalidade última da ação humana, a dimensão subjetiva e o uso que o elemento psíquico faz dos bens formais, passa a se tornar refém dos objetos que ela mesma cria. Assim, Simmel afirma que mesmo não existindo cultura subjetiva sem cultura objetiva, já que o processo cultural e o desenvolvimento do sujeito passam, necessariamente, pela incorporação de objetos cultivados, a cultura objetiva podese tornar independente. ${ }^{5}$

0 fundamental a ser percebido é que a autonomia da cultura objetiva está relacionada às características de complexidade social e extensa divisão do trabalho da sociedade moderna. Os objetos tornam-se mais intelectualizados, controlados por uma lógica interna instrumental, ao mesmo tempo em que o cultivo dos sujeitos não se desenvolve proporcionalmente. Neste sentido, Simmel indica que o problema essencial da vida moderna é ocasionado pelo fato de os objetos serem cada vez mais cultivados sem que os homens sejam capazes de extrair deles um caminho para o aperfeiçoamento de suas vidas subjetivas. 0 espaço essencial da manifestação deste problema, em que se explicitam suas conseqüências aos indivíduos, encontra-se na metrópole.

4 Id. Ibid. p. 232.

5 Id. Ibid. p. 234. 


\section{Metrópole e VidA MODERNA}

Segundo Simmel, o caráter específico da vida mental da metrópole é bastante distinto do registro espiritual da cidade pequena, baseada em relações emocionais que, estabelecidas em níveis inconscientes, partem do equilibrio dos costumes tradicionais. ${ }^{6} 0$ caráter metropolitano, diferentemente, partiria do nível consciente da mente, tendo sua característica central vinculada à facilidade em se adaptar às constantes mudanças e contradições. Assim, este caráter não manifesta os distúrbios internos que a mente habitual e emocional possuiria em situações de ajustamento. A partir de sua consciência, o tipo metropolitano cria um órgão protetor às descontinuidades do meio externo e, em vez de reagir emocionalmente, comporta-se de maneira racional e menos sensitiva.

Simmel percebe que isto marcauma transformação do contato interior dos indivíduos perante a realidade exterior, resultando na dissolução do conteúdo pessoal e emocional e na sistematização de formas fluidas. Dada a impossibilidade de uma totalização cognitiva do mundo exterior, o intelecto do indivíduo moderno age por intermédio de um mecanismo subjetivo de defesa às violências è̀ desordem que a metrópole inscreve. 0 resultado essencialé 0 advento da atitude "blasê", que possibilita uma indiferença em relação às distinções e valores dos objetos exteriores, que passam aser percebidos de modo homogêneo. ParaSimmel, somente através desta atitudeépossível ao agente sobreviver às ininterruptas estimulações que os nervos absorvem na cidade, na medida em que o comportamento blaséinterrompe ofluxo de respostas que o corpo perfaz a qualquer incitamento. Articulada com esta atitude está a figura do estrangeiro, ${ }^{8}$ que não aparece submetido a nenhum componente ou tendência particular da sociedade a que se inscreve, relacionando, de um modo peculiar, dimensões de indiferença e de envolvimento.

Simmel percebe este comportamento psíquico como um reflexo subjetivo da economia monetarizada, na medida em que o dinheiro expressa, de forma paralela ao comportamento racional dos indivíduos modernos, as distinções qualitativas dos objetos dentro de um parâmetro indistinto e nivelador. Na medida em que esses indivíduos possuem uma atitude peculiar de indiferença com as pessoas e com os objetos, o dinheiro aparece como mecanismo fundamental para negar a singularidade desse mesmos fatores. Como valor de troca universal, o dinheiro refere-se somente à qualidade comum dos objetos, reduzindo toda individualidade em um mero nível quantitativo. 0 valor deixa

\footnotetext{
6 Id. "The Metropolis and Mental Life" in 1971, Op. cit.

7 Id. ibid. p. 330.

8 Id. "O Estrangeiro" in Georg Simmel: Sociologia (Grandes Cientistas Sociais). São Paulo: Ática, 1983.
} 
de ser uma substância e transforma-se, exclusivamente, em um conceito relacional a outras mercadorias. Por conseguinte, as relações intelectuais resultantes da vida metropolitana passam a tratar as pessoas como meios a determinadas finalidades, refutando os laços emocionais que salientam traços de singularidade.?

É clara, portanto, a afinidade da caracterização da modernidade em Simmel e 0 tema do fetichismo exposto por Marx. As relações que Simmel estabelece entre cultura objetiva e cultura subjetiva, quando especificada na ligação que o homem moderno possui com o dinheiro, têm por base as relações entre verdade e ilusão, transparência e fantasmagoria, que Marx denotou como a essência da mercadoria. ${ }^{10} \mathrm{Na}$ concepção de Marx, com a fragmentação do trabalho e a universalização da esfera das mercadorias, circuladas a partir do dinheiro como equivalente universal, as relações entre os homens, fundamentadas nas características sociais do próprio trabalho, passam a não ser mais explicitadas e tornam-se nebulosas. A consequiência é que somente as mercadorias parecem interagir entre si, e as relações sociais assumem a forma de uma relação entre coisas. Marx nota o fato de as mercadorias serem percebidas como dotadas de vida própria, de modo que passam a ocultar as ligações humanas nas quais estão verdadeiramente baseadas. o dinheiro aparece como a forma acabada do mundo das mercadorias, sendo o mecanismo que dissimula as relações sociais verdadeiras na medida em que converte os trabalhos humanos particulares, como valores de uso, em objetos que necessitam somente circularem entre si mesmos, como valores de troca. ${ }^{11}$

A singularidade da apropriação de Simmel sobre o tema da fetichização das mercadorias está na conexão que estabelece com o tipo psíquico dos indivíduos metropolitanos, inscritos em contextos sócio-econômicos que renegam contatos diretos

9 Simmel percebe o dinheiro como o único fenômeno permanente dentro do contexto de fluxo que se apresenta na modernidade capitalista. Nesse sentido, o dinheiro personifica o movimento contínuo, ao mesmo tempo em que simboliza uma esfera de permanência e totalidade que dá sentido à realidade social. Dentro das relações entre meios e fins, o dinheiro torna-se, portanto, um meio indiferente que se relaciona a todos os fins. Sobre uma exposição concisa sobre a questão ver FrISBY, DAvid. Simmel and Since: Essays on Georg Simmel's Social Theory. London: Routledge, 1992. pp. 80-97.

${ }^{10}$ MarX, Karl. O Capital: Critica da Economia Política livro 1. Rio de Janeiro: Civilização Brasileira, 1998. pp. 53-172.

"Retomando o tema do fetichismo, David Frisby relaciona Simmel com a exposição da Teoria Crítica a respeito do caráter secreto das mercadorias. Isto será sistematizado, por exemplo, por Walter Benjamim, que diagnostica a mercadoria como fonte original das relações sociais da modernidade, satisfazendo um mundo em movimento no qual os valores são transitórios e as relações sociais fugazes. Caberia lembrar, nesse sentido, a concepção de Simmel sobre a moda, que seria a ênfase maior nesta transitoriedade, na medida em que o mercado requer, aceleradamente, novas formas estéticas para produtos que devem ser vendidos imediatamente. FRISBY, DaviD. 1992, 0p. cit. p. 49. 
entre produtor e consumidor. Não é à toa que Simmel exemplifica o estrangeiro na categoria do comerciante, que intermedia as esferas de compra e venda a partir de produtos vindos de fora da comunidade a que pertence. Ao lado da atitude blasé, passam a predominar a dimensão dos interesses particulares e a tendência mental ao egoísmo racionalmente formulado. Ou seja, esboça-se um processo de racionalização que envolve 0 desencadeamento da produção e do comércio em termos de cálculos que buscam os meios mais eficazes de se alcançarem determinados fins individuais, baseados, principalmente, na obtenção de renda. 0 dinheiro personifica, então, estas características comportamentais, denotando, em oposição às qualidades instintivas e soberanas do homem, um alto grau de certeza e precisão objetiva nas relações dos elementos da vida.

0 resultado é que a atitude mental nas relações pessoais é de reserva e estranhamento. Ao mesmo tempo em que a metrópole indica, dada a especialização e a diferenciação advinda com a divisão do trabalho, formas individuais e independentes de existência, ela sistematiza a predominância do espírito objetivo sobre o espírito subjetivo, acarretando um processo de despersonalização que tende a transformar o sujeito em mero meio quantificável. Simmel lembra que a negligência da qualidade individual e a respectiva independência da cultura objetiva, serão os temas essenciais da crítica que Nietzsche dirige à metrópole e à modernidade. ${ }^{12} 0$ problema, definido dialeticamente, é caracterizado na idéia de tragédia da cultura, supondo não somente a autonomia da cultura objetiva, mas, sobretudo, a penetração desta na dimensão do cultivo subjetivo.

\section{Soclabilidade e Aventura: Artifícios LibertáRIos}

Segundo Simmel, dado o caráter descontínuo e fugaz da modernidade, restaria somente uma saída que produza sentido e coerência aos indivíduos: a direção a uma dimensão interior que possibilite, de alguma maneira, a conexão da relação rompida da cultura objetiva com a subjetiva. Ou seja, a construção de uma esfera que estabeleça novas formas de experimentar a realidade, não mais baseadas na atitude blasé. Como veremos abaixo, esta saída libertária de Simmel, ainda que circunscrita em tempo e espaço determinados, distingue sua teoria da efetiva dominação que Weber atribui à modernidade. Dentre as possibilidades de novas experimentações subjetivas, Simmel sugere a sociabilidade e a aventura.

Segundo Simmel, as associações baseadas na sociabilidade são acompanhadas

${ }^{12}$ Simmel, Georg. "The Metropolis and Mental Life" in 1971, Op. cit. p. 338. 
por um sentimento de satisfação e prazer, que as relaciona ao jogo e à arte..$^{13}$ Assim como o jogo e a arte adquirem seu significado simbólico em oposição à seriedade e à rotina, a sociabilidade aparece como a interação que se relaciona perante o conteúdo concreto da vida sem qualquer finalidade definida a priori. Nesse sentido, a sociabilidade produz no indivíduo uma dimensão de dignidade frente ao ambiente social, na medida em que sua personalidade e suas capacidades se tornam elementos essenciais a sua reprodução. A sociabilidade só se manifesta quando compõe um balanço lúdico das esferas subjetiva e objetiva, de forma a não ocasionar uma associação em que se configura um objetivo predeterminado ou em que parâmetros individuais são colocados livremente. Mais especificamente, os indivíduos renunciam tanto ao aspecto objetivo quanto ao subjetivo, de forma a estabelecer uma espécie de interação pura que, baseada em parâmetros de cordialidade e refinamento, édesvinculada do campo do interesse material que acompanha as relações preponderantes da vida moderna. Na pureza de suas manifestações, a sociabilidade não reivindica questões objetivas, restringindo-se às personalidades que compõem a interação. A temporalidade desta é especificada em seu próprio momento, não postulando uma coerência a um plano futuro, a não ser uma lembrança fugaz.

Ainda que a sociabilidade seja somente um símbolo da vida concreta, sendo instituída, antes, como um jogo, ela se nutre de uma forma específica desta mesma vida. Simmel argumenta que assim como a sociabilidade aparece distante da realidade, sua natureza está diretamente relacionada a ela. 0 fundamental é notar, portanto, que é dado ao indivíduo a oportunidade de sair de sua vida formal e sem significado em direção a um jogo simbólico em que a existência social adquire dinâmica e vitalidade, salientando sentimentos que permanecem, na maior parte do tempo, objetivados.

De forma semelhante, Simmel concebe a aventura constituindo-se em oposição à rotina e sua totalidade objetiva. ${ }^{14} \mathrm{~A}$ aventura tende a incorporar uma idéia de sonho, muitas vezes esquecida, na medida em que não faz parte do processo significativo da vida como um todo, salientando uma parte da existência que, por si só, aparece como uma unidade integrada. Nesse sentido, a aventura se distancia do ego normalizado e da direção da vida assim organizada, instituindo o risco e o enfrentamento experimental do cotidiano. 0 aventureiro surge como modelo do homem desvinculado da história, que vive de forma intensa o presente e não estabelece uma relação causal, racionalmente calculada, entre passado e futuro. 0 elemento imprevisível e o acaso não aparecem como

13 Id. "Sociability" in 1971, Op. cit.

14 Id. "The Adventurer" in 1971, Op. cit. 
problemas, vinculando-se a uma esfera sentimental, não orgânica ao mundo objetivo, que dásignificado real à experiência.

A aventura e a sociabilidade são definidas pelo fato de possuírem significado em virtude do peso que a subjetividade possui em sua caracterização, superando os aspectos racionais da vida. Assim, essas duas formas sociais não constituem contradições efetivas à vida, mas surgem como modos diferentes de experimentá-la, possibilitando, ainda que de maneira circunscrita, uma relação especial das dimensões subjetiva e objetiva que tende a ocasionar alguma liberdade aos indivíduos. Por outro lado, ambas as formas possuem uma qualidade estética que possibilita o retorno do cultivo de sentimentos e arranjos emocionais que a ligam a uma experiência artística. Simmel sugere que há uma relação explícita entre 0 artista e 0 aventureiro, na medida em que a obra de arte recorta uma parte específica da sequiência da experiência individual cotidiana, dandothe uma forma auto-suficiente e potencialmente libertária. ${ }^{15}$

\section{Dimensão Estética e Cultura Objettva}

As dimensões da estética e dos juízos expressados pelos indivíduos em suas possibilidades de criação artística surgem como modos diversos de experimentar a realidade moderna. Segundo David Frisby, a ênfase de Simmel nas formase qualidades de interação indica seu interesse em revelar uma condição estética na rotina social, pois o prazer que sentimos em relação a um objeto seria determinado pela constituição de um conjunto que resulta de uma ligação particular entre partes diversas. ${ }^{16}$ Nesse sentido, o juízo estético não seria determinado por conceitos definidos de maneira objetiva, mas por algo subjetivo que satisfaz um sentimento de harmonia, manifestado quando se cria, paralelamente às relações entre o objetivo e o subjetivo, uma totalidade a partir do fragmentário.

Contudo, a caracterização da estética na vida moderna sofreria as consequiências da economiamonetária amadurecida, certificadorade um mundo reificadoe alienante. Aquestão essencial estávinculada à distância queo dinheiro ocasionaem contraste aos objetos, relacionada à atitude de indiferença frente aos seus valores reais. A predominância da dimensão monetária dentro da arte estaria exemplificada pelo advento das artes aplicadas edos estilos, que marcam a dominação da técnica sobre a subjetividade, reivindicando uma utilidade do produto, um meio em detrimento de uma finalidade livre. As grandes exposições de arte, compostas de enorme diversidade de impressões e imagens, seriam eventos que induziriam a atitude de

\footnotetext{
15 Id. ibid. p. 189-190.
}

${ }^{16}$ FRISBY, DAnD. “The Aesthetics of Modern Life: Simmel's Interpretation. Theory, Culture 7 Societyv. 8n. 3. New York, 1991. 
indiferença e superficialidade na apropriação do significado das obras de arte. Adominação do valor de troca sobre o valor de uso impossibilita uma avaliação estética dos objetos, dada a incapacidade de avaliação qualitativa. ${ }^{17}$

Nesse sentido, o fundamental é perceber nesta concepção estética da modernidade o tema central de Simmel: uma experimentação que refuta a relação do objeto com a subjetividade humana. No caso da obra de arte, nega-se a excitação ocasionada quando reconciliamos o mundo subjetivo com o reino objetivo, incorporando a individualidade da obra a uma dimensão de totalidade. Simmel indica, portanto, a subordinação da estética aos interesses monetários, de forma que o gozo que perpassa a experiência estética se torna anulado, o que nega sua potencialidade em permitir, assim como a sociabilidade e a aventura, novas experiências subjetivas do mundo.

As possibilidades circunscritas de libertação manifestadas na teoria de Simmel serão questionadas pelo trabalho de Weber, na medida em que a obra do último não enfatiza a caracterização de uma experiência individual, mas, sobretudo, fatos estruturais que alcançam, no seu limite, a totalidade da vida moderna. Por outro lado, de forma semelhante a Simmel, o que se percebe como fator decisivo na teoria social de Weber é uma concepção da modernidade que salienta, por meio do entendimento de uma dominação racional-legal, uma direção à objetivação do mundo. Cabe notar, porém, que há uma mudança conceitual fundamental, pois a cultura objetiva em Weber toma a forma de racionalidade, assim como a cultura subjetiva é indicada pela questão da individuação e da pluralidade de valores.

\section{MaX Weber: Religlāo e Racionalidade Moderna}

Uma das melhores formas para a percepção do entendimento de Weber sobre os dilemas da modernidade é basear-se em sua sociologia da religião, que indica, por meio das diferenças dos diversos tipos de composições espirituais, os parâmetros fundamentais que estruturaram a racionalidade moderna. Weber procura identificar as atitudes básicas em relação ao mundo que são motivadas pela religião, principalmente o impacto que esta possui na esfera dos valores individuais. Schluchter afirma que a teoria sociológica de Weber não se propõe a formular uma teoria da racionalidade, mas concebe, ao invés

\footnotetext{
${ }^{17}$ Contudo, segundo Frisby, o problema torna-se mais complexo quando Simmel admite que a economia monetária satisfaz uma outra possibilidade de estética. Nesse sentido, a esfera da circulação das mercadorias criaria uma ilusão particular, submetida a uma valorização invertida baseada em dimensões utilitárias. FRISBY, DAviD. 1991, Op. cit.
} 
disso, uma tipologia dos racionalismos religiosos considerados a partir de seus desenvolvimentos históricos particulares ${ }^{18}$ Esta tipologia sugere que a realidade pode assumir uma variedade de formas racionais, não sendo o propósito da sociologia conferir valor a qualquer dessas formas.

Weber caracteriza a racionalidade ocidental a partir de uma reconstrução histórica que focaliza as relações que a atitude calculada do ascetismo protestante, contraposta ao comportamento aquisitivo tradicional, manteve com a dimensão econômica ${ }^{19}$ Devido a sua concepção religiosa, somente o Ocidente veio conhecer um tipo nunca antes experimentado de capitalismo, baseado na organização racional da produção, assentada no trabalho livre. Weber enfatiza que o mero desejo de ganho ilimitado não se identifica com o capitalismo e seu espírito, mas somente a intenção de uma apropriação que é racionalmente calculada, significando uma utilização planejada de recursos de tal forma que ao final de um período haja algum capital excedente. 0 espírito do capitalismo seria exemplificado nas exposições de Benjamim Franklin, que manifesta a idéia do dever do indivíduo honesto em relação ao aumento de seu capital, tomado como um fim em si mesmo. Assim, a obtenção de dinheiro está combinada com o afastamento do gozo espontâneo da vida, destituindo qualquer caráter hedonista. ${ }^{20}$

0 ponto fundamental é que esta ética expressa um sentimento que está relacionado a idéias religiosas particulares do protestantismo tradicional, que enfatizava uma moral religiosa vinculada ao trabalho secular, visto como vocação queédistribuída aos homens através de uma divisão elaborada por Deus. Assim, ganhar dinheiro legalmente seria expressão de virtude manifestada em uma vocação, o que gera uma obrigação do indivíduo frente ao conteúdo de uma atividade profissional que é relacionada a dotes sagrados. Weber declara, então, que foi a ênfase do significado ascético de uma vocação que passou a propiciar uma justificação ética para a moderna divisão do trabalho. A vocação era percebida como uma ordem divina, a qual cada um deveria se adaptar, principalmente quando se efetivasse o lucro, entendido como um chamado de Deus. 0 poder da devoção religiosa colocava à disposição do mercado trabalhadores sóbrios e industriosos, que percebiam a desigual distribuição de riqueza como obra especial da divina providência. A riqueza só seria condenável na medida em que levasse à vadiagem e ao consumo

${ }^{18}$ Schluchter, Wolfgang. "Weber's Sociology of Rationalism and Typology of Religious Rejections of the World" in Max Weber, Rationality and Modernity. London: Allen \& Unwin, 1987. p. 92.

19 Weber, Max. A Ética Protestante e o Espírito do Capitalismo. São Paulo: Pioneira, 1996.

${ }^{20}$ Weber lembra que mesmo esta ética possui, de um ponto de vista exterior ao seu contexto, algo de irracional, na medida em que a obtenção de quantidades maiores de dinheiro se coloca como algo superior à felicidade ou utilidade material dos indivíduos. WeBER, Max. 1996, Id. Ibid. p. 33. 
luxuoso. Na medida em que foi se estendendo a influência da concepção puritana, a vida econômica racional e burguesa baseada na idéia do bomo economicus era normalizada.

Entretanto, enquanto esta ética se difundia, uma dialética social era instituída: o homem passava a ser dominado pelo próprio produto que tinha criado visando sua libertação - no caso, a libertação religiosa da vida mundana. Segundo Weber, a modernidade enfatiza a desvinculação da conduta econômica perante a ética religiosa. Nenhum fato seria mais claro, nesse sentido, que a tendência das pessoas dominadas pelo espírito do capitalismo serem hostis a qualquer esfera sagrada. As teorias econômicas convencionais passariam a afirmar que a interferência da religião na economia seria tão prejudicial quanto a intervenção do Estado. Por meio de sua pressão econômica, o capitalismo passou a determinar seus próprios mecanismos de reprodução, tornando-se dominantee emancipando-se de seus antigos suportes religiosos. Portanto, o descolamento entre a cultura subjetiva e a cultura objetiva declarado por Simmel transparece aqui de forma correlata, na medida em que o capitalismo, assim como o dinheiro, não possui mais necessidade extrínseca para ser justificado, objetivando-se de tal forma em torno da idéia de um progresso auto-ajustável que a crença religiosa no dever vocacional seria esquecida. Weber sugere que as preocupações com bens materiais acabam por ocasionar uma "prisão de ferro", ${ }^{21}$ pois o comportamento maximizador em busca de riqueza, associado a paixões puramente mundanas, passa a assumir uma crescente força sobre os homens, tornando-se um fim em si mesmo.

\section{CONFUCIONISMO: um CONTRASTE À RACIONALIDADE INSTRUMMENTAL}

Na medida em que Weber defende que o racionalismo está relacionado a um tipo de atitude que encara de forma consciente o mundo a partir dos valores incorporados pelos indivíduos, uma racionalidade consistente poderia ser percebida em diferentes culturas. Por outro lado, o interesse em formações racionais diversas manifesta uma contraposição que ressalta os aspectos particulares dos valores do ascetismo protestante. Assim, a análise weberiana sobre o confucionismo, ${ }^{22}$ por exemplo, possibilita uma maior clareza ao entendimento da racionalidade econômica que, peculiar à cultura ocidental, passou a predominar na modernidade.

Segundo Weber, o confucionismo caracterizava-se, em oposição ao cristianismo, por um agnosticismo e uma percepção negativa em relação a um além extraterreno. 0

${ }^{21}$ Id. Ibid. p. 131.

${ }^{22}$ Id. The Religion of China: Confucionism and Taoism. New York: The Free Press, 1951. 
interesse em valores ou destinos transcendentais permanecia subordinado à influência dos espíritos presentes na realidade concreta. Nesse sentido, o confucionismo significava um ajustamento em relação às ordens e às convenções do mundo, de modo que, quem cumpria os mandamentos tradicionais e mundanos estava, seguramente, livre de pecados. A diferença medular do confucionismo em relação para a religião ocidental estava baseada na dimensão irracional do primeiro, na medida em que o confuciano não lidava de uma maneira consciente com seus próprios interesses, delegando uma ampla esfera de suas ações à magia. Segundo Weber, o julgamento do nível de racionalização de uma religião estava articulado a dois critérios básicos: 0 grau de afastamento em relação à magia; 0 o grau das relações de Deus com o mundo, de modo a perceber a força que uma orientação ético-religiosa exerce. ${ }^{23}$ Assim, o protestantismo aparece como ápice de uma religião racionalizada. Em contraste com a ética não sistematizada do confucionismo, a ética protestante se vinculava ao mundo de uma maneira explícita, gerando grandes tensões à existência humana, uma vez que toda demanda "racional" de acordo com as normas religiosas tinha como obstáculo a realidade, que pedia resoluções "não-racionais". Isto seria de importância fundamental, pois, como Schluchter sugere, a teoria religiosa apresentada por Weber baseia-se nos fatos de afirmação e de rejeição do mundo, que são vistos como dois pontos de vista que tentam ultrapassar, tanto teórica quanto praticamente, o problema da irracionalidade. ${ }^{24} \mathrm{~A}$ afirmação do mundo teria como conteúdo aceitar a realidade como a melhor possível, minimizando o problema da irracionalidade, enquanto a rejeição do mundo intensificaria a irracionalidade na teoria e na prática.

0 que caracterizava 0 ascetismo protestante era exatamente a tentativa de controlar o mundo de acordo com imperativos sagrados, representando sua rejeição a ele sob a forma de ação concreta. Nesse sentido, Weber distingue as diferentes atitudes religiosas antes e depois da reforma para exibir um contraste de um caráter racional e metódico que tenta moldar o mundo de acordo com seus valores - com uma atitude contemplativa, fundamentada emocionalmente - que tende a se deslocar e rejeitar as questões mundanas. A consequiência do confucionismo em relação aos aspectos econômicos foi uma atitude contraposta à racionalidade monetária do ascetismo protestante. Ainda que os relatos dos viajantes tenham notado a preocupação dos nativos chineses em relação ao dinheiro, nunca se caracterizou a administração racional e metódica que são os pressupostos da economia capitalista. $\mathrm{Na}$ medida em que as religiões com fortes imperativos se encontravam em estado de tensão com as irracionalidades e imprevisibilidades do mundo,

${ }^{23}$ Id. Ibid. p. 226.

${ }^{24}$ SCHLUCHTER, WOLFGANG. 1987, Op. cit. p. 98. 
a esfera da magia se tornava cada vez mais limitada. Aética confuciana de uma afirmação e ajustamento ao mundo pressupunha, diferentemente, a existência da magia, não originando a tensão do protestantismo, que se baseava em um Deus que exigia normas e ações consistentes aos valores por ele manifestados. Além disso, havia no confucionismo um argumento em favor da pluralidade das almas, que ocasionava uma oposição à idéia de personalidade presente no 0cidente. 0 indivíduo confuciano era uma finalidade em si mesmo, enquanto o protestante aparecia apenas como uma ferramenta de Deus, que deveria se basear em um modo de conduta racional e previsível.

As consequiências da conduta racional do ascetismo protestante, com sua definição do mundo como algo que deveria ser moldado e controlado, não poderiam ser mais fortes. A tentativa de sistematização do comportamento terreno viria a propiciar 0 desenvolvimento de uma estrutura objetiva que atacaria, posteriormente, até mesmo a própria teodicéia religiosa que teria sido seu fundamento. Como modelo exemplar da direção à objetivação do mundo, a racionalidade econômica do protestantismo acaba por destruir sua própria subjetividade religiosa. 0 paroxismo desse processo teve como apoio essencial a ciência, de modo que o que antes era visto como um esquema racional de crença e conhecimento se torna irracional e destituído de sentido.

\section{Desencantamento do Mundo e Dominação Burocrática: CIÊNCIA E ORdem Institucional MOderna}

Segundo Weber, na medida em que o comportamento racional do capitalismo foi influenciado pelo desenvolvimento das possibilidades técnicas, uma dependência à ciência foi gerada. ${ }^{25}$ Ainda que a origem de segmentos da ciência tenha sido elaborada fora do Ocidente, sua utilização técnica foi encorajada por condições econômicas peculiares que só se encontravam no ambiente ocidental. Nesse sentido, a ciência aparecia relacionada ao desencantamento do mundo, caracterizado pelas demandas por sua crescente intelectualização e racionalização. A crença desencantada postulava que os homens poderiam controlar os fatos da vida por intermédio do cálculo e da técnica, sem necessidade de se recorrer a meios mágicos. Partindo da necessidade de previsibilidade, bastaria que se encontrasse o conceito adequado a cada esfera da vida para se apreender o que se concebia como o verdadeiro ser e seu agir adequado. A vocação da ciência significaria, portanto, a resposta à pergunta de como os homens deveriam viver de acordo com a natureza, conectada

25 Weber, Max. "A Ciência como Vocação" in Ciência e Política: Duas Vocações. São Paulo: Cultrix. 1993. 
à crença de que poderíamos ter um conhecimento desvinculado da alma pessoal e de forças incalculáveis. ${ }^{26}$

Entretanto, ao contrário da concep̧̧ão idealizada dos protagonistas da ciência, 0 que sobressai na caracterização weberiana da modernidadeéo pessimismo circunstanciado nos processos de racionalização, intelectualização, edesencantamento do mundo, que as crenças científicas ajudavam a desenvolver. Ainda que a ciência permitisse 0 esclarecimento em relação aos valores que cada indivíduo possui, estes tendem ase retirar da vida pública, seja em direção ao reino transcendental, seja para as relações diretas e pessoais. Deve-se lembrar que Weber entendeu a pluralidade de valores, ocasionada pela racionalização científica e econômica, tanto como uma esfera de liberdade, quanto como dimensão de perda de autonomia individual, na medida em que impossibilitava um processo de formação identitária que unisse os indivíduos. Como lembra Sam Whimster, a teoria weberiana indica que a sociedade moderna seria caracterizada por uma separação das ordens política, econômica, intelectual, científica, e pessoal. ${ }^{27}$ Cada ordem manteria a validade e a autonomia de seus próprios valores, levando à inevitabilidade do pluralismo. Percebendo uma direção à restrição da subjetividade em um contexto social que objetiva uma diversidade, Weber postula que a resolução dos conflitos resultantes estaria na contenção da dimensão pessoal, que não deveria se intrometer na esfera pública. Assim, ele defende que o verdadeiro funcionário público não deveria fazer política exatamente devido a sua vocação em administrar de forma isenta e não partidária. ${ }^{28} \mathrm{Em}$ relação aos políticos, especificamente, deveria haver um balanceamento das dimensões da ética da convicção, portadora das paixões e dos valores subjetivos, e do sentido de responsabilidade, composto de um comportamento socialmente previdente. Seria por meio dessa conjunção que se formaria um homem autêntico, que poderia aspirar à "vocação política". ${ }^{29}$ Assim, se teria uma composição política que, unindo uma atividade tanto apaixonada quanto calculada, indicasse a possibilidade de mudanças efetuadas dentro de um procedimento gradual e restritivo que atentasse para as consequiências das ações a todos os indivíduos.

${ }^{26}$ Contudo, a tese de Weber é de que viveríamos apenas em um sentido diferente dos antigos, em um novo tipo de encantamento. A crise em que a ciência se inscreve foi gerada por sua impossibilidade de dar respostas generalizantes dentro de um contexto social que torna irreversível a pluralidade de valores. Segundo Weber, a ciência teria de reconhecer suas limitações, contribuindo com a sociedade por meio da dotação de clareza aos significados das condutas individuais, referentes a seus valores específicos. Assim, a ciência cumpriria uma atitude de auto-esclarecimento, articulando-se com um "sentido de responsabilidade". WEBER, Max. Id. Ibid.

${ }^{27}$ WhimSTER, Sim. "The Secular Ethic and the Culture of Modernism" in Max Weber, Rationality and Modernity. London: Allen \& Unwin, 1987. p. 260.

28 WeBER, MAX. 1993, Op. cit.

${ }^{29}$ Id. Ibid. p. 122. 
0 ponto fundamental é que, dada a diferenciação ocasionada pela pluralidade de valores, não haveria mais possibilidade de sistematizações sociais abrangentes, sob pena de se criarem seitas fanáticas. A consciência dos sentidos dos comportamentos individuais, por um lado benéfica, levava, também, a um processo de objetivação que acabava por limitar a movimentação social dirigida para formas sociais potencialmente libertárias, fundadas na experimentação e em fatores emocionais. A política limita-se à disciplina que torna os partidos veículos despersonalizados que se assemelham a máquinas. Por sua vez, a circunscrição da política ao voto nada mais faz do que transformar os cidadãos da sociedade de massa em ferramentas para um poder descaracterizado. ${ }^{30}$

Nesse sentido, o caminho àdominação burocrática, baseada em uma valorização da neutralidade, torna-se cada vez mais fundamentado. Entre os fatores de importância incontestável da teoria weberiana, encontram-se as estruturas racionais e formais do direito e da administração que, paralelamente ao desenvolvimento do capitalismo moderno, são determinadas pelos meios técnicos da ciência. Somente com estas estruturas seria possibilitado o desenvolvimento de uma atitude baseada no cálculo seguro. Segundo Weber, a administração burocrática é aquela vinculada a uma legislação fundamentada e documentada a partir do ponto de vista estritamente formal, tornando-se o modo mais racional de dominação porque alcança eficiência em virtude da generalização de precisão e disciplina a todas as tarefas. ${ }^{31}$

0 interessante é que a argumentação de Weber sugere a inevitabilidade dessa dominação no ambiente moderno, caracterizado pela pluralidade de valores. Assim, uma vez que a administração burocrática é a mais racional do ponto de vista técnicoformal, fundada no conhecimento profissional condicionado pela produção de bens, ela seria inevitável para a administração de uma sociedade de massa, caracterizada por ampla diversidade no trabalho e nos valores. Nesse sentido, a burocracia não é imposta por um ator social determinado, definindo-se como um conhecimento que tem a tendência de se fortalecer pelo seu próprio saber prático. Segundo Weber, mesmo com uma revolução socialista, 0 aparelho burocrático seria obrigado a continuar funcionando, em virtude dos interesses materiais mais fundamentais. ${ }^{32}$ Sem a burocracia, a existência

${ }^{30}$ Entretanto, a teoria de Weber tende, por vezes, a vislumbar uma saída à racionalidade formal. Como Johannes Weiss sintetiza, o processo de racionalização exposto por Weber é caracterizado por tensões internas. Assim, ainda que Weber se refira às tendências da racionalização ocidental à burocratização no plano institucional e ao desencantamento do mundo no plano cultural, em nenhum momento afirma serem estes fatos irreversíveis, assumindo a possibilidade do surgimento de velhos ideais, vinculados, principalmente, ao advento de mobilizações carismáticas. Ver WeIss, JohnnNes. "On the Irreversibility of Western Rationalization and Max Weber's Alleged Fatalism" in Max Weber, Rationality and Modernity. London: Allen \& Unwin, 1987

31 Weber, Max. Economia e Sociedade v.1. Brasilia: Editora UnB, 1994. pp. 142-7.

${ }^{32}$ Id. Ibid. p. 146. 
de uma sociedade com ampla separação entre funcionários, empregados e trabalhadores, seria impossível, a menos para aqueles que encontrassem, autonomamente, seus meios de subsistência. Somente uma pequena organização social poderia dispensar a necessidade de uma administração contínua, rigorosa e calculável.

No plano individual, nada mais tão similar ao descolamento da objetividade de dimensões subjetivas como especificara Simmel, já que a dominação burocrática significa a ascendência da impessoalidade formalista a partir de um nivelamento intersubjetivo, não havendo lugarparapaixões ou entusiasmos. Como naéticaprotestante, oquese colocaéo dever anteriormentedefinido, sem considerações pessoais. A tendência comportamental resultanteé uma execução materialmente utilitarista das tarefas administrativas.

Enfim, a dominação burocrática define precisamente como 0 ascetismo religioso tornou possível não somente o controle do mundo, mas definitivamente, o controle sobre os homens. Como Jeffrey Alexander nota, a despersonalização e autodisciplina ocasionadas por este ascetismo promoveram uma autonomia restrita do indivíduo, definida como um distanciamento às emoções. ${ }^{33}$ Assim, o fundamental éperceber que a capacidade de se tornar uma ferramenta em favor de Deus permitiu a despersonalização e objetivação dos agentes sociais, sendo a burocracia a manifestação estrutural mais exemplar deste espírito abstrato.

\section{COMEnTÁRios Finais}

Segundo Sam Whimster, a questão essencial das teorias de Simmel e Weber é circunstanciada em torno da problemática, que se coloca ao homem moderno, de como afirmar seus valores em face das estruturas objetivas.$^{34}$ Ao mesmo tempo em que édado a esse indivíduo uma crescente consciência sobre este problema, seu poder se torna menor. Ainda que Simmel esboce alguma saída de se controlar o destino individual em certas esferas minimalistas, Weber parece pessimista a essa realidade, formada, no seu entender, por uma dominação que cobre todos os aspectos da vida, inclusive a dimensão política. A diferença entre ambos os autores está baseada no fato de que a análise de Weber não pressupõe a potencialidade das experiências estéticas, como os paraísos artificiais da sociabilidade e da aventura de Simmel, por exemplo, postulavam.

Nesse sentido, éo tema da experimentação subjetiva que distingue o pensamento de Simmel da caracterização estrutural da modernidade exposta por Weber, concebida como

33 ALEXANDER, JeFFrEy. "The Dialectic of Individuation and Domination: Weber's Rationalization Theory and Beyond" in Max Weber, Rationality and Modernity. London: Allen \& Unwin, 1987.

34 WHIMSTER, SAM. 1987, Op. cit. 
dominação fundamentada nas formas do Estado e da burocracia. A percepção an alítica de Simmel está condicionada por uma experimentação individual baseada no fluxo e na transitoriedade, de modo que a realidade social nãoéentendida, exclusivamente, como uma totalidade pré-ordenada, como se pode argumentar a partir da análise weberiana. Simmel parece, a todo momento, procurar incorporar àsua teoria conteúdos psíquicos que o indivíduo moderno experimenta. Assim, sua teoria relaciona-se, por exemplo, tanto à tradiçãof filosófica de Nietzsche a respeito das questões do embate entre ressentimento e subjetividade quanto à perspectiva do cuidado de si elaborada por Foucault. E não poderia ser de outra forma, se notarmos que a questão central de sua teseéfundada nas relações entre o ambientesubjetivoe os aspectos objetivos da vida, em que as características externas dasociedadesão, necessariamente, manifestadas nas almas individuais.

Contudo, mesmo que difiram em algumas questões normativas, a ontologia da modernidade produzida pela teoria de ambos indica a mesma preocupação: o dilema da con̉scientização individual perante a objetivação do mundo. A racionalização das relações sociais notada por Simmel no contexto da economia monetária foi, sem dúvida, reforçada pela concepção social e política proposta por Weber. 0 desencantamento do mundo, visto por Weber a partir da dominação de uma racionalidade que tendia a desconstruir 0 significado do mundo, pressupõe, em seus postulados centrais, a mesma desconexão da cultura objetiva à cultura subjetiva percebida por Simmel.

Por conseguinte, são evidentes as relações do comportamento calculador do ascetismo protestante com a transformação social gerada pela economia monetária que Simmel denotava, em que todos os objetos da vida se tornam fins em si mesmo, e não meros meios àsubjetividade particular. 0 entendimento fundamental de ambas as teorias quanto à modernidade reivindica a perda de criatividade e liberdade individual, na medida em que se torna cada vez mais difícil uma individualidade que contrarie as finalidades suscitadas pela cultura objetiva.

Por outro lado, as teorias indicam as contradições pelas quais os indivíduos presentes no espaço da economia liberal se inscrevem. Ao contrário dos postulados que enfatizam uma esfera autônoma de escolha, as análises de Simmel e Weber demonstram as aporias e limites que uma concepção voltada exclusivamente ao indivíduo perfaz. Os autores evidenciam, diferentemente, a centralidade do caráter estrutural que a modernidade apresenta, o que sugere um ambiente que manifesta restrições a um comportamento livre. Assim, o agente maximizador não épressuposto operando em uma situação social isenta de imperativos, mas inscrito em formas culturais que escapam a seu controle. Além disso, seus trabalhos salientam a forma histórica pela qual o modelo de indivíduo 
moderno, idealmente portador de interesses autônomos, foi construído, contrariando as proposições que aludem um movimento social que é definido pela soma ou agregação de vontades independentes.

Enfim, ambos os autores especificam problemas que irão influenciar a teoria social e política ao longo do século XX. 0 tema da objetivação das condições sociais pode ser perfeitamente exemplificado, por exemplo, no diagnóstico de Habermas sobre 0 descolamento entre sistema e mundo da vida, de forma que as orientações integradoras do último são direcionadas sistemicamente, refutando o advento de uma reflexividade autônoma. Fundamentalmente, essas análises atacam o pressuposto iluminista sobre a emancipação individual, sendo a modernidade exposta, tanto como esfera de potencialidade política, quanto como espaço de perda de significado subjetivo. Nesse sentido, no contexto contemporâneo de apatia política, as análises de Simmel e Weber parecem essenciais em ampliar o debate sobre a necessidade de uma sistematização social que indique a possibilidade de um projeto emancipador, revertendo o próprio dilema caracterizado por ambos.

Recebido em setembro de 2004. 